\title{
Development of a ductile fracture model considering stress triaxiality and Lode angle influences
}

\author{
Mehdi Ganjiani $^{1}$ and Milad Homayounfard ${ }^{1}$ \\ ${ }^{1}$ University of Tehran College of Engineering
}

August 13, 2020

\begin{abstract}
In this paper, a fully-involved anisotropic failure model including the effect of stress triaxiality and Lode angle proposed by Ganjiani [Ganjiani, M., 2020. A damage model for predicting ductile fracture with considering the dependency on stress triaxiality and Lode angle. European Journal of Mechanics-A/Solids, 104048] is extended to predict the fracture phenomena in the ma-terials. For considering the anisotropy effects, Hill's 48 yield function is used. The proposed model is applied to construct the fracture loci and the corresponding Fracture Forming Limit Diagram (FFLD) to validate the performance of the model. The fully-involved anisotropic means that in constructing FFLD, the anisotropy is involved on both the stress triaxiality and the fracture strain. The predicted results are in good agreement with the experimental data over a wide range of stress triaxialities. Comparison between the current model and some fracture criteria is also provided, and the results indicate the significant potential of the model to predict ductile fracture as well as FFLD especially for anisotropic materials.
\end{abstract}

\section{Hosted file}

rev05 - Development of a ductile fracture model.pdf available at https://authorea.com/ users/350717/articles/475474-development-of-a-ductile-fracture-model-considering-stresstriaxiality-and-lode-angle-influences

\section{Hosted file}

rev05 - Development of a ductile fracture model.doc available at https://authorea.com/ users/350717/articles/475474-development-of-a-ductile-fracture-model-considering-stresstriaxiality-and-lode-angle-influences 